\title{
CLC-3 channels in cancer (Review)
}

\author{
SEN HONG ${ }^{1,2^{*}}$, MIAOMIAO BI ${ }^{3 *}$, LEI WANG ${ }^{2}$, ZHENHUA KANG $^{2}$, \\ LIMIAN LING ${ }^{2}$ and CHUNYAN ZHAO ${ }^{1}$
}

\author{
${ }^{1}$ Department of Physiology, The Basic Medical College, Jilin University, Changchun 130021; \\ ${ }^{2}$ Department of Colon and Anal Surgery, The First Hospital of Jilin University, Jilin University, \\ Changchun 130021; ${ }^{3}$ Department of Ophthalmology, The China-Japan Union Hospital of \\ Jilin University, Jilin University, Changchun 130033, P.R. China
}

Received July 28, 2014; Accepted October 30, 2014

DOI: $10.3892 / o r .2014 .3615$

\begin{abstract}
Ion channels are involved in regulating cell proliferation and apoptosis (programed cell death). Since increased cellular proliferation and inhibition of apoptosis are characteristic features of tumorigenesis, targeting ion channels is a promising strategy for treating cancer. CLC-3 is a member of the voltage-gated chloride channel superfamily and is expressed in many cancer cells. In the plasma membrane, CLC-3 functions as a chloride channel and is associated with cell proliferation and apoptosis. CLC-3 is also located in intracellular compartments, contributing to their acidity, which increases sequestration of drugs and leads to chemotherapy drug resistance. In this review, we summarize the recent findings concerning the involvement of CLC-3 in cancer and explore its potential in cancer therapy.
\end{abstract}

\section{Contents}

1. Introduction

2. CLC-3 in cancer

3. CLC-3 and VRACs in cell proliferation

4. CLC-3 in drug resistance

5. Targeting CLC-3 in the treatment of cancer

6. Conclusions and perspectives

\section{Introduction}

Ion channels have various and important roles in cellular functions, ranging from the control of cell excitability to the

Correspondence to: Professor Chunyan Zhao, Department of Physiology, The Basic Medical College, Jilin University, 126 Xinmin Street, Changchun 130021, P.R. China

E-mail: zhaochunyanmd@sohu.com

${ }^{*}$ Contributed equally

Key words: CLC-3, cancer, chloride channel, chemotherapeutic resistance, proliferation, apoptosis regulation of cell volume. Channel dysfunctions have been associated with arrhythmias (1), skeletal muscle disorders (2), neurological disorders including epilepsy and migration (3), cystic fibrosis (4) and endocrine disorders such as diabetes (5). There is increasing evidence that ion channel dysfunction is also involved in cancer $(6,7)$; in particular, potassium, sodium, calcium and chloride channels have been shown to contribute to cancer development, metastasis and drug resistance $(8,9)$. Targeting ion channels is a promising strategy for the treatment of cancer (10-12).

Recent studies have shown that ion channels and transporters have crucial roles in regulating cell proliferation, differentiation and apoptosis (13-16). The functions of ion channels include maintenance of membrane potential, cell cycle regulation and control of cell volume and thus contribute to the regulation of cellular processes (16-19). Cancer cells are characterized by the malignant transformation of cells resulting in increased proliferation, aberrant differentiation and reduced apoptosis. Although the mechanisms that control ion channels in cancer are not well understood, it is known that they contribute to cancer pathology by way of changes in the cell cycle and cell volume $(6,7,13)$.

Chloride channels contribute to the regulation of the cell cycle and volume $(7,11,20)$. The process of cell proliferation requires an increase in cell volume for generating daughter cells, while apoptosis is characterized by cell shrinkage (17). The volume-regulated anion channel (VRAC) is a major mechanism through which cells maintain a relatively constant cell volume (6). The VRAC also participates in cell proliferation, differentiation, migration and apoptosis $(21,22)$. Although the identity of the molecule responsible for VRAC-activated cellular swelling has not been established, the protein CLC-3 is a strong candidate (23). CLC-3 encodes a key component of the native VRAC in many cancer cells including that of prostate cancer epithelial, nasopharyngeal carcinoma and malignant glioma (24-26). Knockdown of CLC-3 inhibits endogenous VRAC currents in many cells such as cardiomyocytes, vascular smooth muscle cells and non-pigmented ciliary epithelial cells (27-29). Inhibition of CLC-3 by specific anti-CLC9-3 antibodies reduces the swelling activated by chloride currents in human prostate cancer epithelial cells (25). Furthermore, CLC-3 mediates upregulation of VRAC by the anti-apoptotic 
B-cell lymphoma 2 (BCL2) protein $(22,25)$. Therefore, CLC-3 may function as a VRAC in cancers, participating in cell proliferation and apoptosis.

CLC-3 belongs to the CLC voltage-gated chloride channel superfamily, which includes 2 distinct functional groups: voltage-gated chloride channels and $\mathrm{Cl}^{-} / \mathrm{H}^{+}$antiporters (30). Similar to CLC-4 and CLC-5, CLC-3 functions as a $\mathrm{Cl}^{-} / \mathrm{H}^{+}$ transporter in intracellular membranes $(30,31)$. CLC-4 and CLC-5 have been shown to have an important role in acidification of endosomes and lysosomes $(32,33)$. Knockout of CLC-3 impairs acidification and chloride accumulation in the endosome (34). Increased acidification of intracellular compartments can sequester basic anticancer drugs, thereby decreasing effective concentrations of anticancer drugs and inducing drug resistance (35). Several studies have shown that CLC-3 contributes to the resistance of cancer cells to chemotherapeutic drugs such as etoposide and cisplatin (36-38). Therefore, inhibition of CLC-3 is a potential strategy for increasing sensitivity to chemotherapy.

In this review, we summarize the function of CLC-3 in cancer and discuss the mechanisms by which CLC- 3 contributes to proliferation, apoptosis and drug resistance in cancer cells (Fig. 1). We further explore whether CLC-3 may be a potential strategy for the treatment of cancer.

\section{CLC-3 in cancer}

Several studies have recently shown that CLC-3 participates in cell proliferation, apoptosis, the cell cycle and metastasis in many cancers. These include nasopharyngeal carcinoma, glioma, endometrial cancer and prostate cancer epithelial cells $(25,39-43)$. Here, we review the role of CLC-3 in the proliferation, apoptosis and drug resistance of these cancer cells (Fig. 1 and Table I).

Glioma. Glioma is a lethal brain tumor characterized by strong invasion into surrounding brain tissues $(41,44)$. Glioma cell invasion requires cell volume changes that are regulated by many ion channels, including potassium channels and chloride channels (41). CLC-3 has been shown to have an important role in the invasiveness of human glioma cells $(41,45)$. CLC-3 is abundantly expressed on the cytoplasmic membrane and in intracellular vesicles of glioma cells $(26,41)$. Knockdown of CLC-3 reduces resting outwardly-rectifying chloride currents in glioma cells $(41,46)$, suggesting that CLC-3 mediates resting chloride currents in the plasma membrane and thus may be involved in cell shrinkage during invasion.

The migration of glioma cells is associated with changes in the intracellular $\mathrm{Ca}^{2+}$ concentration (47), and bradykinin has been shown to increase the intracellular $\mathrm{Ca}^{2+}$ concentration via bradykinin $\mathrm{B} 2$ receptors and to induce cell migration along cerebral vasculature (48). Interestingly, CLC-3 can be activated by $\mathrm{Ca}^{2+} /$ calmodulin-dependent kinase II (CAMKII) $(49,50)$. Knockout of CLC-3 was found to reduce $\mathrm{Ca}^{2+}$-activated chloride currents mediated by CaMKII in glioma cells and to decrease bradykinin-induced migration of human glioma cells (51).

CLC-3 also is implicated in premitotic condensation (PMC), a process that involves a decrease in cytoplasmic volume as glioma cells retract processes, round up and progress with mitosis (52). PMC is a crucial step in cell division and is linked to chromatic condensation (52). Knockout of CLC-3 by shRNA reduced PMC-associated outwardly rectifying chloride currents, inhibited the rate of PMC and impaired DNA condensation (26). Furthermore, similar to knockout of CLC-3 by shRNA, the chloride channel blocker 5-nitro-2-3-phenylpropylamino benzoic acid (NPPB) produces a similar effect on PMC, suggesting that the chloride channel function of CLC-3 on the plasma membrane determines the rate at which glioma cells undergo PMC and progress through mitosis (26). Furthermore, activation of CLC-3 by CaMKII is involved in $\mathrm{PMC}$ and accelerates cytoplasmic condensation during glioma cell division (53), suggesting that CaMKII-mediated activation of CLC-3 contributes to PMC.

Nasopharyngeal carcinoma. Nasopharyngeal carcinoma cells abundantly express CLC-3 (39,54-56). CLC-3 is located in the plasma membrane, cytoplasm and nuclei in nasopharyngeal carcinoma (CNE-2Z) cells. Under isotonic conditions, knockdown of CLC-3 was found to reduce background chloride currents and to inhibit ATP-induced chloride channels, accompanied by increased cell volume. These findings suggest that CLC-3 constitutes the major background chloride channel under isotonic conditions and may be responsible for maintenance of basal cell volume (56).

The role of CLC-3 in the regulation of cell volume is further supported by several studies showing that knockout of CLC-3 reduced volume-regulated chloride currents in CNE-2Z cells $(39,40,57)$. In addition, CLC-3 was identified as the acid-activated chloride channel in CNE-2Z cells, which can be inhibited by hypertonic solutions (42) and inhibition of the volume-activated chloride channel by CLC-3 knockout was found to be positively correlated with inhibition of cell proliferation and migration in CNE-2Z cells $(24,39)$. This suggests that CLC-3 is involved in cell proliferation and migration via modulation of volume-regulated chloride currents.

Prostate cancer. CLC-3 is expressed in lymph node carcinoma of prostate ( $\mathrm{LNCaP}$ ) cancer epithelial cells (25). Inhibition of CLC-3 by its specific antibodies effectively prevented activation of swelling-activated chloride currents in $\mathrm{LNCaP}$ cells. This suggests that CLC-3 may be the swelling-activated chloride channel in these cells. Furthermore, BCL2 increased the expression of CLC-3, accompanied by an increase in swelling-activated chloride currents, indicating that CLC-3 mediates BCL2-dependent modulation of swelling-activated chloride currents. It has been reported that BCL2 increases the ability of cells to regulate cell volume via upregulation of swelling-activated chloride currents in MDCK (Madin-Darby canine kidney) cells (22). Since cell proliferation is associated with cell volume changes, CLC-3 is likely to contribute to cell volume changes during the proliferation of $\mathrm{LNCaP}$ cells.

Neuroendocrine tumors. CLC-3 has been found to be expressed in several neuroendocrine cell lines including BON (a human pancreatic neuroendocrine carcinoma), CC-18 (a human neuroendocrine-differentiated colonic carcinoma) and QGP-1 (a human pancreatic carcinoma of islet origin) (36). The expression of CLC-3 is predominantly located in the late endosome and lysosome, and overexpression of CLC-3 increases 


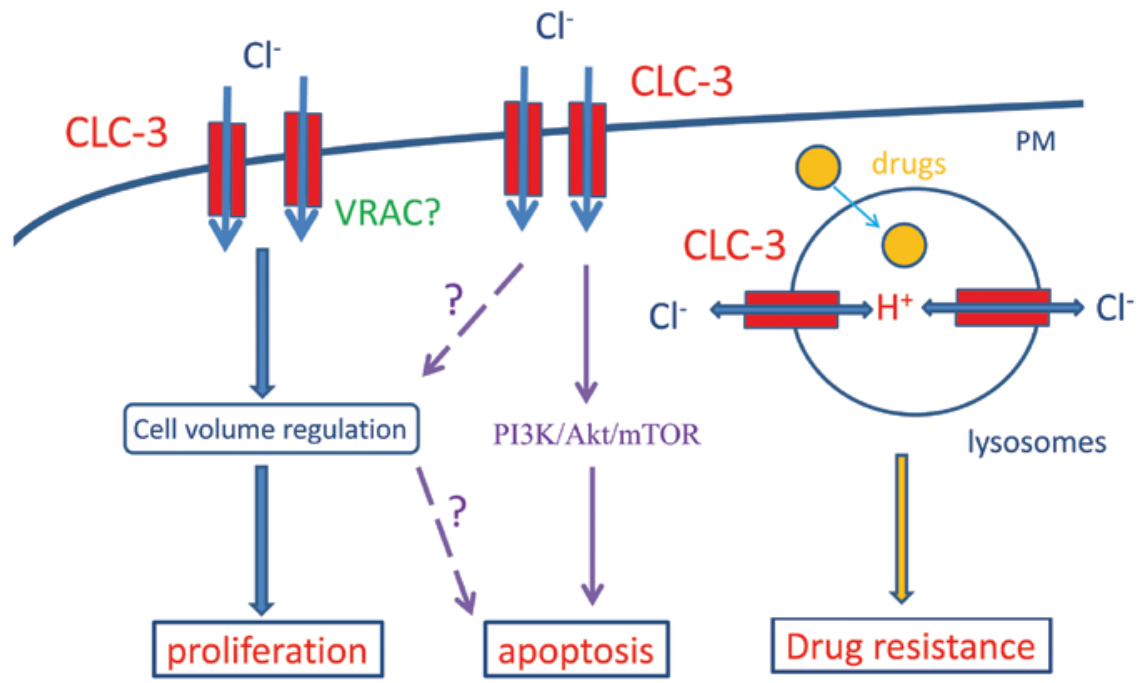

Figure 1. Schematic summarizing the role of CLC-3 in cancer. CLC-3 is expressed on the plasma membrane (PM) and functions as a chloride channel, possibly as a key component of the VRAC, in many cancer cells. CLC-3 is involved in cell proliferation through regulation of cell volume (38). Overexpression of CLC-3 is also associated with apoptosis $(88,89)$ due to inhibition of the PI3K/Akt/mTOR signaling pathway (89). In addition, as a Cl/ $/ \mathrm{H}^{+}$transporter, $\mathrm{CLC}-3$ contributes to the acidity of the late endosome and lysosomes, promoting sequestration of basic chemotherapeutic drugs and leading to drug resistance $(35,37)$. CLC-3 inhibitors can be used for the treatment of cancer by inhibiting cell proliferation and preventing drug resistance, whereas CLC-3 activators exhibit antitumor activity through promotion of apoptosis.

Table I. Roles of CLC-3 in cancer.

\begin{tabular}{|c|c|c|c|}
\hline Cancer type & Channel function & Roles in cancer & References \\
\hline \multirow[t]{2}{*}{ Glioma } & $\begin{array}{l}\text { Resting outwardly rectifying } \\
\text { chloride channel; } \mathrm{Ca}^{2+} \text {-activated } \\
\text { chloride channel mediated } \\
\text { by CaMKII }\end{array}$ & $\begin{array}{l}\text { Cell migration } \\
\text { Cell invasion }\end{array}$ & $(41,45,46,51)$ \\
\hline & $\begin{array}{l}\text { Outwardly rectifying chloride } \\
\text { channel associated with } \\
\text { premitotic condensation }\end{array}$ & $\begin{array}{l}\text { Cell volume regulation } \\
\text { Regulation of premitotic } \\
\text { condensation } \\
\text { Cell cycle regulation } \\
\text { Cell mitosis } \\
\text { Cell division }\end{array}$ & $(26,53)$ \\
\hline Nasopharyngeal carcinoma & $\begin{array}{l}\text { Background chloride channel; } \\
\text { ATP-induced chloride channel; } \\
\text { volume-regulated chloride channel; } \\
\text { acid-activated chloride } \\
\text { channel }\end{array}$ & $\begin{array}{l}\text { Cell volume regulation } \\
\text { Cell proliferation } \\
\text { Cell migration } \\
\text { Cell apoptosis } \\
\text { Cell cycle progression }\end{array}$ & $(24,39,40,42,56,57,89)$ \\
\hline Prostate cancer & Volume-regulated chloride channel & $\begin{array}{l}\text { Cell volume regulation } \\
\text { Cell apoptosis? }\end{array}$ & $(25)$ \\
\hline Neuroendocrine tumors & $\mathrm{Cl}^{-}-\mathrm{H}^{+}$transporter & $\begin{array}{l}\text { Increased acidity of } \\
\text { intracellular vesicles } \\
\text { Drug resistance }\end{array}$ & $(36)$ \\
\hline
\end{tabular}

CAMKII, calmodulin-dependent kinase II.

the acidity of intracellular vesicles. In addition, overexpression of CLC-3 decreased the cytotoxicity of the chemotherapeutic drug etoposide in human carcinoid BON cells. Since weakly basic chemotherapeutic drugs such as etoposide can be sequestered to acidic intracellular membrane compartments, the expression of CLC-3 may confer drug resistance to basic chemotherapeutic agents such as etoposide by increasing the acidity of intracellular compartments (58). 


\section{CLC-3 and VRACs in cell proliferation}

Cancer cells are characterized by unlimited proliferation, which is associated with substantial changes in cell volume. During the early phase of cell proliferation, cells synthesize a large amount of proteins, which can result in intracellular hyperosmolarity, thus leading to water influx and cell swelling. Cancer cells maintain their normal size and avoid excessive cell volume changes that can damage structural integrity and cellular functions $(59,60)$. Cell swelling initiates a regulatory volume decrease through activation of many ion channels $\left(\mathrm{K}^{+}\right.$and $\left.\mathrm{Cl}^{-}\right)$to return the cell volume to its normal size. The VRAC is important in the regulation of cell volume (61) and is associated with cell proliferation in various types of cells. These include hepatocytes (62), endothelial cells (63), pulmonary artery smooth muscle cells $(64)$ and cancer cells $(7,65)$.

The molecular characterization of the VRAC is still unclear. CLC-3 has been proposed as the native VRAC in various cells including cardiac myocytes, vascular smooth muscle cells and non-pigmented ciliary epithelial cells $(27-29,66)$. Knockdown of CLC-3 by siRNA and anti-CLC-3 antibodies inhibits swelling-activated chloride currents, suggesting that CLC-3 is an integral component of the VRAC (27-29,66). However, the role of CLC-3 as a native VRAC remains controversial. Several other studies have shown that CLC-3 is predominantly expressed in intracellular compartments and is not the swelling-activated chloride channel $(64,61)$. In addition, the swelling-activated chloride current remains present in CLC-3-knockout mice, arguing against the role of CLC-3 as a native VRAC (67). However, since the properties of native swelling-activated chloride currents are altered in CLC-3knockout mice, accompanied by the altered expression of many proteins (68), it is possible that CLC-3 may be a regulatory component of the VRAC and another protein compensates for the loss of CLC-3 in these knockout mice. Furthermore, a recent study found that endogenous swelling-activated chloride currents are eliminated in inducible cardiac-specific CLC-3 knockout mice (70), suggesting that CLC-3 may be a key component of VRAC in the heart.

CLC-3 has been found in the plasma membrane and is involved in the regulation of cell volume in many types of cancers such as glioma, nasopharyngeal carcinoma and prostate cancer epithelial cells $(25,39-41,57)$. Several lines of evidence have shown that CLC-3 has an important role in cell proliferation in vascular smooth muscle cells via control of the cell cycle $(70,71)$. It has been reported that levels of CLC-3 vary according to the phase of the cell cycle in nasopharyngeal carcinoma cells, i.e. low in the G1 phase and high in the $S$ phase (54). Furthermore, CLC-3 can promote passage of the cells through the G1 phase into the S (39). Suppression of CLC-3 was demonstrated to inhibit swelling-activated chloride currents and decrease regulatory volume, which was correlated with cell proliferation in nasopharyngeal carcinoma cells (39). Therefore, CLC-3 is believed to be involved in cell proliferation and cell cycle progression through regulation of cell volume via the swelling-activated chloride channel (39) (Fig. 1).

Changes in cell volume was correlated with the regulation of cell cycle progression, which during proliferation is generally stimulated by cell swelling and inhibited by cell shrinkage $(72,73)$. In addition, cell volume is greatest in the $\mathrm{M}$ phase and least in the G1 phase and increases in cell volume are associated with the G1-S transition (59). Although it is known that cell volume is associated with cell cycle progression, the regulatory mechanisms remain unclear. Recently, Zhang et al (40) found that in nasopharyngeal carcinoma cells, CLC-3 is a downstream target of cyclin D1, which controls cell cycle progression through regulation of cyclin-dependent kinases (CDKs). Cyclin D1 promotes the protein expression of CLC-3, associated with an increase in volume-activated chloride channels, suggesting that cyclin D1 regulates volume-activated chloride currents via upregulation of CLC-3 expression. In addition, inhibition of CDK4 activated volume-activated chloride currents, whereas blockade of CDK6 reduced these currents (40). These results suggest that the cyclin D1-CDK4 complex may inhibit the VRAC and the cyclin D1-CDK6 complex may activate the VRAC. It appears that cyclin D1 can mediate cell cycle progression and regulate cell volume via CLC-3. Furthermore, it has been reported that cell swelling stimulates extracellular signal regulated kinase (ERK1/2) (59,74,75), and ERK activity regulates the induction of cyclin D1 (76-78). Therefore, it appears that cell volume regulates cell cycle progression via control of cyclin D1.

CLC-3 in cell apoptosis. A characteristic hallmark of apoptosis is cell shrinkage or apoptotic volume decrease (AVD). AVD occurs early in apoptosis in response to apoptotic stimuli and may be a prerequisite $(59,79)$. Most commonly, subsequent to AVD is regulatory volume increase, which allows cells to return to their original cell volume (59). The VRAC has been shown to be involved in AVD (80-82). CLC-3 has been found to contribute to the VRAC in prostate cancer epithelial cells and the anti-apoptotic BCL2 increases swelling-activated chloride currents via upregulation of CLC-3 expression (25). However, since inhibition of VRAC can effectively prevent apoptotic events (83), the finding that BCL2 mediates upregulation of VRAC suggests that BCL2 promotes VRAC-mediated AVD and induces apoptosis. This clearly contradicts the anti-apoptotic function of BCL2. It is possible that CLC-3 may not contribute to the apoptosis-inducing VRAC. Consistent with this idea, Okada et al (84) concluded that CLC-3 is not the volume-sensitive outwardly rectifying chloride channel involved in AVD.

In basilar arterial smooth muscle cells, knockout of CLC-3 increases apoptosis induced by hydrogen peroxide via the intrinsic mitochondrial pathway (85). In human bronchial epithelial cells, overexpression of CLC-3 inhibited transforming growth factor (TGF)- $\beta$ 1-induced apoptosis, which was suppressed by overexpression of BCL2 (86). Knockout of CLC-3 facilitated apoptosis induced by thapsigargin, a specific inhibitor of the endoplasmic reticulum calcium ATPase, in pheochromocytoma-derived PC12 cells (87). These findings suggest that CLC-3 is likely to promote apoptosis in these cells via a different signaling pathway.

Accordingly, in nasopharyngeal carcinoma cells, the expression of CLC-3 was upregulated during early apoptosis and after treatment with paclitaxel. Overexpression of CLC-3 associated with microtubules was involved in paclitaxel-induced apoptosis (88). Furthermore, in nasopharyngeal carcinoma cells activation of CLC-3 by a novel class of CLC-3 
Table II. CLC-3 inhibitors and activators in the treatment of cancer.

\begin{tabular}{|c|c|c|c|}
\hline Targets & Results & Mechanisms & References \\
\hline \multicolumn{4}{|l|}{ CLC-3 inhibitors } \\
\hline $\begin{array}{l}\text { Nonspecific inhibitors } \\
\text { (tamoxifen, NPPB) }\end{array}$ & $\begin{array}{l}\text { Inhibition of cell } \\
\text { proliferation }\end{array}$ & Inhibits chloride currents & $(42,56,57,65,89)$ \\
\hline $\begin{array}{l}\text { Specific CLC-3 } \\
\text { antibodies }\end{array}$ & & Inhibits chloride currents & $(27,68,92)$ \\
\hline CLC-3 knockdown & $\begin{array}{l}\text { Inhibition of proliferation } \\
\text { and apoptosis }\end{array}$ & Inhibits chloride currents & $(41,42,46,56,57,89)$ \\
\hline Chlorotoxin & $\begin{array}{l}\text { Inhibition of cell } \\
\text { migration } \\
\text { Phase I clinical trial }\end{array}$ & $\begin{array}{l}\text { Inhibits CLC- } 3 \text { chloride currents } \\
\text { via the binding with MMP2 }\end{array}$ & $(95-97)$ \\
\hline \multicolumn{4}{|l|}{ CLC-3 activators } \\
\hline Bufadienolides & Antitumor activities & $\begin{array}{l}\text { Inhibits CLC-3 chloride currents } \\
\text { via inhibition of the PI3K/Akt/mTOR } \\
\text { signaling pathway }\end{array}$ & $(89,101)$ \\
\hline
\end{tabular}

NPPB, 5-nitro-2-3-phenylpropylamino benzoic acid.

activators (bufadienolides) induced apoptosis via inhibition of the PI3K/Akt/mTOR signaling pathway (89) (Fig. 1).

\section{CLC-3 in drug resistance}

Multidrug resistance is the main obstacle in the treatment of cancer. Ion channels and transporters that are involved in promotion of cell proliferation and evasion of apoptosis contribute to the development of multidrug resistance $(8,81)$. As discussed above, overexpression of CLC-3 is associated with increased cell proliferation. Thus, CLC-3 may be related to multidrug resistance in cancer cells via increased cell proliferation. Consistent with this idea, suppression of CLC-3 was found to increase the sensitivity of human glioma U251 cells to cisplatin via inhibition of Akt and autophagy (37).

CLC-3 is expressed in late endosomes and lysosomes and contributes to their acidity. Increasing the acidity of intracellular compartments confers drug resistance to weakly basic chemotherapeutic drugs. Therefore, overexpression of CLC-3 may increase sequestration of basic drugs in acidic compartments, thus leading to drug resistance (Fig. 1). This hypothesis has been proven by the finding that overexpression of CLC-3 increases drug resistance to etoposide by increasing acidification of the late endocytic compartment in BON cells (36). Similarly, $\mathrm{Xu}$ et al (38) reported that in erythroleukemia K562 and RK562 cells, upregulation of CLC-3 by NPPB increased acidification of intracellular compartments and promoted sequestration of cisplatin, conferring drug resistance to cisplatin.

\section{Targeting CLC-3 in the treatment of cancer}

As described above, increased expression of CLC-3 in cancer cells stimulates proliferation and migration, but also increases apoptosis. It appears to be paradoxical that cancer cells can manage to upregulate CLC-3 to promote proliferation and migrate, while at the same time avoiding its pro-apoptotic effect. Because the expression of CLC-3 is cell cycle-dependent (high in the $\mathrm{S}$ and low in the G1 phase) (39), transient upregulation of CLC-3 at specific stages between the G1 and $\mathrm{S}$ phases may promote cell cycle progression, leading to cancer cell proliferation. In contrast, persistent upregulation of CLC-3 may lead to apoptosis.

The mechanisms by which cancer cells evade apoptosis induced by upregulation of CLC-3 remain unclear. Since CLC-3 is regulated by anti-apoptotic BCL2 in prostate cancer cells (25) and BCL2 upregulation is required for the progression of prostate cancer cells (90), it may be that cancer cells can upregulate anti-apoptotic proteins such as BCL2 to inhibit the pro-apoptotic effect of CLC-3.

CLC-3 is involved in cell proliferation and apoptosis and contributes to drug resistance in many cancer cells (Fig. 1). CLC-3 inhibitors can be used for blocking cancer cell proliferation and increasing chemosensitivity, whereas CLC-3 activators can promote cancer cell apoptosis. Therefore, developing novel CLC-3 inhibitors and activators may be a strategy for the treatment of cancer (Table II).

CLC-3 inhibitors. A highly specific CLC-3 inhibitor is preferred for use in cancer therapy, to reduce nonspecific side effects. Unfortunately, specific CLC-3 inhibitors have not been developed. Several chloride channel inhibitors such as tamoxifen and NPPB have been shown to inhibit CLC-3 currents and reduce proliferation of many cancer cells $(42,56,57,65,89)$. However, these inhibitors are not specific for CLC-3. They can block other chloride channels such as $\mathrm{Ca}^{2+}$-activated chloride channel anoctamin 1 (also known as transmembrane member 16A or TMEM16A) (91) and therefore are not used as specific CLC-3 blockers. As far as cancer therapy is concerned, these 
inhibitors are not suitable to use because chloride channel inhibition is wide-ranging. Developing specific compounds for a chloride channel such as CLC-3 remains a major challenge.

Specific CLC-3 targeting can be affected by developing CLC-3-specific antibodies. Several studies have shown that CLC-3 antibodies can effectively inhibit CLC-3 currents $(27,68,92)$. It has been reported that antibodies against human Eag1 potassium channels display antitumor activity both in vitro and in vivo (93). However, it remains to be determined whether antibodies against CLC-3 can be used for the treatment of cancer.

Specific inhibition of CLC-3 can be obtained by knockdown of CLC-3 with siRNAs. Knockdown of CLC-3 by specific siRNA has been used in many in vitro studies and effectively inhibits CLC-3 currents and CLC-3-mediated proliferation and apoptosis $(41,42,46,56,57,89)$. However, the use of siRNA in cancer therapy has not been tested in animals or clinical studies.

Chlorotoxin, a 36-amino acid peptide that is isolated from a scorpion toxin, was originally regarded as a chloride channel inhibitor (94). Chlorotoxin targets glioma cells specifically by binding to matrix metalloproteinase-2 (MMP-2) (95). A recent study by Qin et al (96) confirmed that MMP-2 mediates the target delivery from chlorotoxin-modified liposomes to tumors. This study also indicated that chlorotoxin inhibited CLC-3 chloride currents by binding with MMP-2, resulting in inhibition of cell migration in gliomas (96) and suggested that chlorotoxin may also target other cancers with high MMP-2 expression. A phase I clinical trial of a synthetic chlorotoxin derivative labelled with iodine-131 was completed with adult patients with recurrent high-grade glioma and a single dose of this compound was well tolerated (97).

CLC-3 activator. Recently, bufadienolides were discovered to be CLC-3 activators with antitumor activities (89). Of the 7 compounds tested, bufalin exhibited the most potent antitumor activity and induced the largest chloride currents, which were blocked by CLC-3 siRNA. Furthermore, bufalin induced apoptosis via inhibition of the PI3K/Akt/mTOR signaling pathway. Knockout of CLC-3 reduced bufalin-induced apoptosis. These findings suggest that bufalin exerts its antitumor activity via activation of CLC-3 chloride currents, leading to inhibition of the PI3K/Akt/mTOR signaling pathway.

In addition, it has been reported that bufadienolides are associated with antitumor activity through various other mechanisms, including p21-dependent cell cycle arrest, induction of mitochondria-dependent and death receptor-mediated apoptosis and inhibition of anti-apoptotic proteins such as BCL2 (98). It remains to be determined whether CLC-3 is involved in these antitumor mechanisms affected by bufadienolides. However, bufadienolides may not be safe to use, due to high toxicity $(99,100)$. A recent study showed that bufadienolides in poloxamer-modified liposomes improved antitumor efficacy and reduced toxicity (101) and these may provide a safe way to deliver bufadienolides for the treatment of cancer.

\section{Conclusions and perspectives}

CLC-3 participates in the process of proliferation, apoptosis and drug resistance in many types of cancers, including nasopharyngeal carcinoma, glioma, endometrial cancer and prostate cancer epithelial cells $(25,39-43)$. Whether CLC-3 is the native VRAC is debatable, but CLC-3 has been found to be a component of the VRAC in many cancer cells. Inhibition of CLC- 3 currents by channel blockers, CLC- 3 antibodies and CLC-3 siRNA can effectively reduce cancer cell proliferation. Furthermore, CLC- 3 contributes to the acidity of intracellular compartments, in which basic chemotherapeutic drugs can be sequestered, with subsequent chemoresistance. Inhibition of CLC3 can increase the sensitivity of cancer cells to chemotherapeutic drugs. In addition, CLC-3 contributes to the apoptosis of cancer cells and CLC-3 activators can promote this. Taken together, targeting CLC-3 could be a therapeutic strategy for the treatment of cancer.

There are many challenges to overcome before CLC-3 can be used in the treatment of cancer. Although CLC-3 currents have been associated with proliferation and apoptosis $(39,88,89)$, the specific signaling pathway responsible for this is unclear. It is also essential that the different roles of CLC-3 in apoptosis and proliferation should be elucidated - it remains to be determined whether a specific CLC-3 activator that promotes cell apoptosis increases cell proliferation, thus leading to increased tumor growth, migration and invasion and whether a specific CLC-3 blocker that inhibits cell proliferation could reduce cell apoptosis. There is also very little knowledge regarding the expression of CLC-3 in tumor tissues of either animal models or cancer patients or the role of CLC-3 at different stages of cancer development. Finally, highly specific blockers and activators for CLC- 3 are not available.

A major obstacle in implementing anti-CLC-3 therapy is that targeting CLC-3 may inhibit the normal functions of CLC-3 in non-cancer tissues. It is known that CLC-3 is widely expressed in many tissues, including the brain, and mice with disrupted CLC-3 exhibit signs of neurodegeneration $(67,102)$. This problem needs to be solved before CLC-3 inhibitors can be used in the treatment of cancer. Further research into the mechanisms of CLC-3 in carcinogenesis may result in the development of novel drugs targeting CLC-3, which could serve as therapeutic tools in the treatment of cancer.

\section{References}

1. Marban E: Cardiac channelopathies. Nature 415: 213-218, 2002.

2. Platt D and Griggs R: Skeletal muscle channelopathies: new insights into the periodic paralyses and nondystrophic myotonias. Curr Opin Neurol 22: 524-531, 2009.

3. Catterall WA, Dib-Hajj S, Meisler MH and Pietrobon D: Inherited neuronal ion channelopathies: new windows on complex neurological diseases. J Neurosci 28: 11768-11777, 2008.

4. Planells-Cases R and Jentsch TJ: Chloride channelopathies. Biochim Biophys Acta 1792: 173-189, 2009.

5. Rolim AL, Lindsey SC, Kunii IS, et al: Ion channelopathies in endocrinology: recent genetic findings and pathophysiological insights. Arq Bras Endocrinol Metabol 54: 673-681, 2010.

6. Lehen'kyi V, Shapovalov G, Skryma R and Prevarskaya N: Ion channels and transporters in cancer. 5. Ion channels in control of cancer and cell apoptosis. Am J Physiol Cell Physiol 301: C1281-C1289, 2011.

7. Kunzelmann K: Ion channels and cancer. J Membr Biol 205: 159-173, 2005.

8. Hoffmann EK and Lambert IH: Ion channels and transporters in the development of drug resistance in cancer cells. Philos Trans R Soc Lond B Biol Sci 369: 20130109, 2014.

9. Lang F and Stournaras C: Ion channels in cancer: future perspectives and clinical potential. Philos Trans R Soc Lond B Biol Sci 369: 20130108, 2014. 
10. Li M and Xiong ZG: Ion channels as targets for cancer therapy Int J Physiol Pathophysiol Pharmacol 3: 156-166, 2011.

11. Arcangeli A, Crociani O, Lastraioli E, Masi A, Pillozzi S and Becchetti A: Targeting ion channels in cancer: a novel frontier in antineoplastic therapy. Curr Med Chem 16: 66-93, 2009.

12. Conti M: Targeting ion channels for new strategies in cancer diagnosis and therapy. Curr Clin Pharmacol 2: 135-144, 2007.

13. Bortner CD and Cidlowski JA: Ion channels and apoptosis in cancer. Philos Trans R Soc Lond B Biol Sci 369: 20130104, 2014

14. Becchetti A, Munaron L and Arcangeli A: The role of ion channels and transporters in cell proliferation and cancer. Front Physiol 4: 312, 2013.

15. Prevarskaya N, Skryma R, Bidaux G, Flourakis M and Shuba Y: Ion channels in death and differentiation of prostate cancer cells. Cell Death Differ 14: 1295-1304, 2007.

16. Lang F, Foller M, Lang KS, et al: Ion channels in cell proliferation and apoptotic cell death. J Membr Biol 205: 147-157, 2005.

17. Lang F, Foller M, Lang K, et al: Cell volume regulatory ion channels in cell proliferation and cell death. Methods Enzymol 428: 209-225, 2007.

18. Urrego D, Tomczak AP, Zahed F, Stuhmer W and Pardo LA Potassium channels in cell cycle and cell proliferation. Philos Trans R Soc Lond B Biol Sci 369: 20130094, 2014.

19. Blackiston DJ, McLaughlin KA and Levin M: Bioelectric controls of cell proliferation: ion channels, membrane voltage and the cell cycle. Cell Cycle 8: 3527-3536, 2009.

20. Abdul M and Hoosein N: Expression and activity of potassium ion channels in human prostate cancer. Cancer Lett 186: 99-105, 2002.

21. Nilius B, Eggermont $J$, Voets $T$ and Droogmans G: Volume-activated $\mathrm{Cl}^{-}$channels. Gen Pharmacol 27: 1131-1140, 1996.

22. Shen MR, Yang TP and Tang MJ: A novel function of BCL-2 overexpression in regulatory volume decrease. Enhancing swelling-activated $\mathrm{Ca}(2+)$ entry and $\mathrm{Cl}(-)$ channel activity. J Biol Chem 277: 15592-15599, 2002.

23. Duan DD: The CLC-3 chloride channels in cardiovascular disease. Acta Pharmacol Sin 32: 675-684, 2011.

24. Mao J, Chen L, Xu B, et al: Suppression of CLC-3 channel expression reduces migration of nasopharyngeal carcinoma cells. Biochem Pharmacol 75: 1706-1716, 2008.

25. Lemonnier L, Shuba Y, Crepin A, et al: Bcl-2-dependent modulation of swelling-activated $\mathrm{Cl}^{-}$current and CLC-3 expression in human prostate cancer epithelial cells. Cancer Res 64: 4841-4848, 2004.

26. Habela CW, Olsen ML and Sontheimer H: CLC3 is a critical regulator of the cell cycle in normal and malignant glial cells. J Neurosci 28: 9205-9217, 2008

27. Wang GX, Hatton WJ, Wang GL, et al: Functional effects of novel anti-CLC-3 antibodies on native volume-sensitive osmolyte and anion channels in cardiac and smooth muscle cells. Am J Physio Heart Circ Physiol 285: H1453-H1463, 2003.

28. Do CW, Lu W, Mitchell CH and Civan MM: Inhibition of swellingactivated $\mathrm{Cl}^{-}$currents by functional anti-CLC-3 antibody in native bovine non-pigmented ciliary epithelial cells. Invest Ophthalmol Vis Sci 46: 948-955, 2005.

29. Zhou JG, Ren JL, Qiu QY, He H and Guan YY: Regulation of intracellular $\mathrm{CI}^{-}$concentration through volume-regulated CLC-3 chloride channels in A10 vascular smooth muscle cells. J Biol Chem 280: 7301-7308, 2005

30. Duran C, Thompson CH, Xiao Q and Hartzell HC: Chloride channels: often enigmatic, rarely predictable. Annu Rev Physiol 72: 95-121, 2010

31. Guzman RE, Grieschat M, Fahlke C and Alekov AK: CLC-3 is an intracellular chloride/proton exchanger with large voltage-dependent nonlinear capacitance. ACS Chem Neurosci 4 : 994-1003, 2013.

32. Scheel O, Zdebik AA, Lourdel $S$ and Jentsch TJ: Voltage-dependent electrogenic chloride/proton exchange by endosomal CLC proteins. Nature 436: 424-427, 2005.

33. Picollo A and Pusch M: Chloride/proton antiporter activity of mammalian CLC proteins CLC-4 and CLC-5. Nature 436 : 420-423, 2005.

34. Hara-Chikuma M, Yang B, Sonawane ND, Sasaki S, Uchida S and Verkman AS: CLC-3 chloride channels facilitate endosomal acidification and chloride accumulation. J Biol Chem 280: 1241-1247, 2005

35. Rajagopal A and Simon SM: Subcellular localization and activity of multidrug resistance proteins. Mol Biol Cell 14: 3389-3399, 2003 .
36. Weylandt KH, Nebrig M, Jansen-Rosseck N, et al: CLC-3 expression enhances etoposide resistance by increasing acidification of the late endocytic compartment. Mol Cancer Ther 6 : 979-986, 2007.

37. Su J, Xu Y, Zhou L, et al: Suppression of chloride channel 3 expression facilitates sensitivity of human glioma U251 cells to cisplatin through concomitant inhibition of Akt and autophagy. Anat Rec (Hoboken) 296: 595-603, 2013.

38. Xu Y, Zheng H, Kang JS, et al: 5-Nitro-2-(3-phenylpropylamino) benzoic acid induced drug resistance to cisplatin in human erythroleukemia cell lines. Anat Rec (Hoboken). 294: 945-952, 2011.

39. Xu B, Mao J, Wang L, et al: CLC-3 chloride channels are essential for cell proliferation and cell cycle progression in nasopharyngeal carcinoma cells. Acta Biochim Biophys Sin (Shanghai) 42: 370-380, 2010.

40. Zhang H, Zhu L, Zuo W, et al: The CLC-3 chloride channel protein is a downstream target of cyclin D1 in nasopharyngeal carcinoma cells. Int J Biochem Cell Biol 45: 672-683, 2013.

41. Sontheimer H: An unexpected role for ion channels in brain tumor metastasis. Exp Biol Med (Maywood) 233: 779-791, 2008

42. Wang L, Ma W, Zhu L, et al: CLC-3 is a candidate of the channel proteins mediating acid-activated chloride currents in nasopharyngeal carcinoma cells. Am J Physiol Cell Physiol 303: C14-C23, 2012.

43. Li M, Wu DB and Wang J: Effects of volume-activated chloride channels on the invasion and migration of human endometrial cancer cells. Eur J Gynaecol Oncol 34: 60-64, 2013.

44. Wen PY and Kesari S: Malignant gliomas in adults. N Engl J Med 359: 492-507, 2008.

45. Lui VC, Lung SS, Pu JK, Hung KN and Leung GK: Invasion of human glioma cells is regulated by multiple chloride channels including CLC-3. Anticancer Res 30: 4515-4524, 2010.

46. Olsen ML, Schade S, Lyons SA, Amaral MD and Sontheimer H: Expression of voltage-gated chloride channels in human glioma cells. J Neurosci 23: 5572-5582, 2003

47. Jantaratnotai $\mathrm{N}$ and McLarnon JG: Calcium dependence of purinergic subtype $\mathrm{P}_{2} \mathrm{Y}_{1}$ receptor modulation of $\mathrm{C} 6$ glioma cell migration. Neurosci Lett 497: 80-84, 2011.

48. Montana V and Sontheimer H: Bradykinin promotes the chemotactic invasion of primary brain tumors. J Neurosci 31 4858-4867, 2011.

49. Cuddapah VA and Sontheimer H: Molecular interaction and functional regulation of CLC-3 by $\mathrm{Ca}^{2+} /$ calmodulin-dependent protein kinase II (CaMKII) in human malignant glioma. J Biol Chem 285: 11188-11196, 2010.

50. Huang P, Liu J, Di A, et al: Regulation of human CLC-3 channels by multifunctional $\mathrm{Ca}^{2+} /$ calmodulin-dependent protein kinase. J Biol Chem 276: 20093-20100, 2001.

51. Cuddapah VA, Turner KL, Seifert $\mathrm{S}$ and Sontheimer $\mathrm{H}$ : Bradykinin-induced chemotaxis of human gliomas requires the activation of KCa3.1 and CLC-3. J Neurosci 33: 1427-1440, 2013.

52. Habela CW and Sontheimer H: Cytoplasmic volume condensation is an integral part of mitosis. Cell Cycle 6: 1613-1620, 2007.

53. Cuddapah VA, Habela CW, Watkins S, Moore LS, Barclay TT and Sontheimer H: Kinase activation of CLC-3 accelerates cytoplasmic condensation during mitotic cell rounding. Am J Physiol Cell Physiol 302: C527-C538, 2012.

54. Wang LW, Chen LX and Jacob T: CLC-3 expression in the cell cycle of nasopharyngeal carcinoma cells. Sheng Li Xue Bao 56: 230-236, 2004

55. Ye D, Zhang HF, Zhu LY, Wang LW and Chen LX: CLC-3 siRNA inhibits regulatory volume decrease in nasopharyngeal carcinoma cells. Nan Fang Yi Ke Da Xue Xue Bao 31: 216-220, 2011 (In Chinese).

56. Yang L, Ye D, Ye W, et al: CLC-3 Is A main component of background chloride channels activated under isotonic conditions by autocrine ATP in nasopharyngeal varcinoma cells. J Cell Physiol 226: 2516-2526, 2011.

57. Zhu L, Yang H, Zuo W, et al: Differential expression and roles of volume-activated chloride channels in control of growth of normal and cancerous nasopharyngeal epithelial cells. Biochem Pharmacol 83: 324-334, 2012.

58. Raghunand N, Martinez-Zaguilan R, Wright SH and Gillies RJ $\mathrm{pH}$ and drug resistance. II. Turnover of acidic vesicles and resistance to weakly basic chemotherapeutic drugs. Biochem Pharmacol 57: 1047-1058, 1999.

59. Hoffmann EK, Lambert IH and Pedersen SF: Physiology of cell volume regulation in vertebrates. Physiol Rev 89: 193-277, 2009.

60. Lang F: Mechanisms and significance of cell volume regulation. J Am Coll Nutr 26: S613-S623, 2007. 
61. Sardini A, Amey JS, Weylandt KH, Nobles M, Valverdez MA and Higgins CF: Cell volume regulation and swelling-activated chloride channels. Biochim Biophys Acta 1618: 153-162, 2003.

62. Wondergem R, Gong W, Monen SH, et al: Blocking swelling-activated chloride current inhibits mouse liver cell proliferation. J Physiol 532: 661-672, 2001.

63. Nilius B, Prenen J, Kamouchi M, Viana F, Voets $T$ and Droogmans G: Inhibition by mibefradil, a novel calcium channel antagonist, of $\mathrm{Ca}(2+)$ - and volume-activated $\mathrm{Cl}^{-}$channels in macrovascular endothelial cells. Br J Pharmacol 121: 547-555, 1997.

64. Liang W, Huang L, Zhao D, et al: Swelling-activated $\mathrm{Cl}^{-}$currents and intracellular CLC-3 are involved in proliferation of human pulmonary artery smooth muscle cells. J Hypertens 32 : 318-330, 2014.

65. Shen MR, Droogmans G, Eggermont J, Voets T, Ellory JC and Nilius B: Differential expression of volume-regulated anion channels during cell cycle progression of human cervical cancer cells. J Physiol 529: 385-394, 2000.

66. Duan D, Winter C, Cowley S, Hume JR and Horowitz B Molecular identification of a volume-regulated chloride channel. Nature 390: 417-421, 1997.

67. Stobrawa SM, Breiderhoff T, Takamori S, Engel D, Schweizer M, Zdebik AA, Bösl MR, Ruether K, Jahn H, Draguhn A, Jahn R and Jentsch TJ: Disruption of CLC-3, a chloride channel expressed on synaptic vesicles, leads to a loss of the hippocampus. Neuron 29 : 185-196, 2001.

68. Yamamoto-Mizuma S, Wang GX,Liu LL, et al: Altered properties of volume-sensitive osmolyte and anion channels (VSOACs) and membrane protein expression in cardiac and smooth muscle myocytes from Clcn $3^{--}$mice. J Physiol 557: 439-456, 2004

69. Xiong D, Heyman NS, Airey J, et al: Cardiac-specific, inducible CLC-3 gene deletion eliminates native volume-sensitive chloride channels and produces myocardial hypertrophy in adult mice. J Mol Cell Cardiol 48: 211-219, 2010.

70. Wang GL, Wang XR, Lin MJ, He H, Lan XJ and Guan YY: Deficiency in CLC-3 chloride channels prevents rat aortic smooth muscle cell proliferation. Circ Res 91: E28-E32, 2002.

71. Tang YB, Liu YJ, Zhou JG, Wang GL, Qiu QY and Guan YY: Silence of CLC-3 chloride channel inhibits cell proliferation and the cell cycle via G/S phase arrest in rat basilar arterial smooth muscle cells. Cell Prolif 41: 775-785, 2008.

72. Rouzaire-Dubois B, O'Regan S and Dubois JM: Cell size-dependent and independent proliferation of rodent neuroblastoma x glioma cells. J Cell Physiol 203: 243-250, 2005.

73. Dubois JM and Rouzaire-Dubois B: The influence of cell volume changes on tumour cell proliferation. Eur Biophys J 33: 227-232, 2004.

74. Van der Wijk T, De Jonge HR and Tilly BC: Osmotic cell swellinginduced ATP release mediates the activation of extracellular signal-regulated protein kinase (Erk)-1/2 but not the activation of osmo-sensitive anion channels. Biochem J 343: 579-586, 1999.

75. Sadoshima J, Qiu Z, Morgan JP and Izumo S: Tyrosine kinase activation is an immediate and essential step in hypotonic cell swelling-induced ERK activation and c-fos gene expression in cardiac myocytes. EMBO J 15: 5535-5546, 1996.

76. Modi PK, Komaravelli N, Singh N and Sharma P: Interplay between MEK-ERK signaling, cyclin D1 and cyclin-dependent kinase 5 regulates cell cycle reentry and apoptosis of neurons. Mol Biol Cell 23: 3722-3730, 2012.

77. Cohen JD, Gard JM, Nagle RB, Dietrich JD, Monks TJ and Lau SS: ERK crosstalks with 4EBP1 to activate cyclin D1 translation during quinol-thioether-induced tuberous sclerosis renal cell carcinoma. Toxicol Sci 124: 75-87, 2011.

78. Ravenhall C, Guida E, Harris T, Koutsoubos V and Stewart A The importance of ERK activity in the regulation of cyclin D1 levels and DNA synthesis in human cultured airway smooth muscle. Br J Pharmacol 131: 17-28, 2000.

79. Bortner CD, Hughes FM Jr and Cidlowski JA: A primary role for $\mathrm{K}^{+}$and $\mathrm{Na}^{+}$efflux in the activation of apoptosis. J Biol Chem 272: 32436-32442, 1997.

80. Eggermont J, Trouet D, Carton I and Nilius B: Cellular function and control of volume-regulated anion channels. Cell Biochem Biophys 35: 263-274, 2001.

81. Pedersen SF, Hoffmann EK and Novak I: Cell volume regulation in epithelial physiology and cancer. Front Physiol 4: 233 , 2013.
82. Stutzin A and Hoffmann EK: Swelling-activated ion channels: functional regulation in cell-swelling, proliferation and apoptosis Acta Physiol (Oxf) 187: 27-42, 2006.

83. Maeno E, Ishizaki Y, Kanaseki T, Hazama A and Okada Y Normotonic cell shrinkage because of disordered volume regulation is an early prerequisite to apoptosis. Proc Natl Acad Sci USA 97: 9487-9492, 2000.

84. Okada Y, Shimizu T, Maeno E, Tanabe S, Wang X and Takahashi N: Volume-sensitive chloride channels involved in apoptotic volume decrease and cell death. J Membr Biol 209: 21-29, 2006

85. Qian Y, Du YH, Tang YB, et al: CLC-3 chloride channel prevents apoptosis induced by hydrogen peroxide in basilar artery smooth muscle cells through mitochondria dependent pathway. Apoptosis 16: 468-477, 2011.

86. Cheng G, Shao Z, Chaudhari B and Agrawal DK: Involvement of chloride channels in TGF-betal-induced apoptosis of human bronchial epithelial cells. Am J Physiol Lung Cell Mol Physiol 293: L1339-1347, 2007.

87. Zhang HN, Zhou JG, Qiu QY, Ren JL and Guan YY: CLC-3 chloride channel prevents apoptosis induced by thapsigargin in PC12 cells. Apoptosis 11: 327-336, 2006.

88. Zhang H, Li H, Yang L, et al: The CLC-3 chloride channel associated with microtubules is a target of paclitaxel in its induced-apoptosis. Sci Rep 3: 2615, 2013.

89. Liu J, Zhang D, Li Y, et al: Discovery of bufadienolides as a novel class of CLC-3 chloride channel activators with antitumor activities. J Med Chem 56: 5734-5743, 2013.

90. Lin Y, Fukuchi J, Hiipakka RA, Kokontis JM and Xiang J: Up-regulation of $\mathrm{Bcl}-2$ is required for the progression of prostate cancer cells from an androgen-dependent to an androgenindependent growth stage. Cell Res 17: 531-536, 2007.

91. Yang YD, Cho H, Koo JY, et al: TMEM16A confers receptoractivated calcium-dependent chloride conductance. Nature 455 1210-1215, 2008.

92. Jin NG, Kim JK, Yang DK, et al: Fundamental role of CLC-3 in volume-sensitive $\mathrm{Cl}^{-}$channel function and cell volume regulation in AGS cells. Am J Physiol Gastrointest Liver Physiol 285 G938-948, 2003.

93. Gomez-Varela D, Zwick-Wallasch E, Knotgen $\mathrm{H}$, et al Monoclonal antibody blockade of the human Eag1 potassium channel function exerts antitumor activity. Cancer Res 67 7343-7349, 2007.

94.DeBin JA and Strichartz GR: Chloride channel inhibition by the venom of the scorpion Leiurus quinquestriatus. Toxicon 29 1403-1408, 1991.

95. Deshane J, Garner CC and Sontheimer H: Chlorotoxin inhibits glioma cell invasion via matrix metalloproteinase-2. J Biol Chem 278: 4135-4144, 2003.

96. Qin C, He B, Dai W, et al: The impact of a chlorotoxin-modified liposome system on receptor MMP-2 and the receptor-associated protein CLC-3. Biomaterials 35: 5908-5920, 2014.

97. Mamelak AN, Rosenfeld S, Bucholz R, et al: Phase I singledose study of intracavitary-administered iodine-131-TM-601 in adults with recurrent high-grade glioma. J Clin Oncol 24 3644-3650, 2006

98. Newman RA, Yang P, Pawlus AD and Block KI: Cardiac glycosides as novel cancer therapeutic agents. Mol Interv 8 36-49, 2008.

99. Abdel-Rahman MA, Ahmed SH and Nabil ZI: In vitro cardiotoxicity and mechanism of action of the Egyptian green toad Bufo viridis skin secretions. Toxicol In Vitro 24: 480-485, 2010

100. Barrueto F Jr, Kirrane BM, Cotter BW, Hoffman RS and Nelson LS: Cardioactive steroid poisoning: a comparison of plant- and animal-derived compounds. J Med Toxicol 2: $152-155,2006$

101. Hu K, Zhu L, Liang H, Hu F and Feng J: Improved antitumor efficacy and reduced toxicity of liposomes containing bufadienolides. Arch Pharm Res 34: 1487-1494, 2011.

102. Yoshikawa M, Uchida S, Ezaki J, et al: CLC-3 deficiency leads to phenotypes similar to human neuronal ceroid lipofuscinosis Genes Cells 7: 597-605, 2002. 